\title{
Engaging Indigenous Youth in Science with the High-Altitude Balloon Experiment
}

\author{
Stephen Cheng1, Fidji Gendron², Vincent Ziffle², David Gerhard ${ }^{3}$ \\ ${ }^{1}$ Department of Chemistry and Biochemistry, University of Regina, Regina, Canada \\ ${ }^{2}$ Department of Indigenous Science, The Environment and Economic Development, First Nations University of Canada, \\ Regina, Canada \\ ${ }^{3}$ Department of Computer Science, University of Regina, Regina, Canada \\ Email: Stephen.Cheng@uregina.ca
}

How to cite this paper: Cheng, S., Gendron, F., Ziffle, V., \& Gerhard, D. (2019). Engaging Indigenous Youth in Science with the High-Altitude Balloon Experiment. Creative Education, 10, 319-331. https://doi.org/10.4236/ce.2019.102026

Received: December 20, 2018

Accepted: February 17, 2019

Published: February 20, 2019

Copyright $\odot 2019$ by author(s) and Scientific Research Publishing Inc. This work is licensed under the Creative Commons Attribution International License (CC BY 4.0).

http://creativecommons.org/licenses/by/4.0/

(c) (i) Open Access

\begin{abstract}
Our custom high-altitude balloon experiment kit with the complete set of instructions has been successfully used to engage high school and post-secondary students across Canada. This article describes how the high-altitude balloon experiment was adapted to engage Indigenous students from two on-reserve schools in science with the presence of an Elder. Based on the results from our research, while the balloon experiment is an effective tool to engage Indigenous students, the project doesn't change the participants' interest in science. We are making several suggestions to bring the experiment to its full potential. It would be more beneficial to make the high-altitude balloon experiment as a multi-day workshop or a major component of a science summer camp. Further, it would be more effective to integrate the balloon experiment into the high school science curriculum rather than run it as an independent event in the on-reserve schools. Finally, we are suggesting how student participation of the survey can be improved for on-reserve schools.
\end{abstract}

\section{Keywords}

High-Altitude Balloon Experiment, Indigenous Students, Student Engagement, Science Activity, STEM

\section{Introduction}

Since the early 2000s, post-secondary institutions have been incorporating high-altitude balloon experiments in university science and engineering courses to motivate students (Coleman \& Mitchell, 2014; Faltersack, Maraccini, Petrie, \& Rasmussen, 2016; Larson, Armstrong, \& Hiscock, 2009; Voss \& Dailey, 2011). As discussed by Coleman and Mitchell (2014), the high-altitude balloon experiment 
was initially used specifically in atmospheric science courses; students in those courses would participate in designing atmospheric experiments, launch the balloon, recover the payload, analyze the data, and present the results. Students who participated in the complete experiment were found to be excited about the experience long after the end of program. Further, the hands-on research experience was found to improve students' learning outcomes. In the past few years, some educators saw the potential of the high-altitude balloon experiment; they discussed the launching of high-altitude balloons involving middle school and high school students to engage them in science, technology, engineering and mathematics (STEM) (Beck-Winchatz \& Bramble, 2014; Fong, Kennon, \& Roberts, 2016; Hike \& Beck-Winchatz, 2015; Saad, 2014; Straub, Ingwalson, \& Fevig, 2013; Taylor \& Nero, 2017; Tillman, Roberts, \& Fuller, 2008). It is important to expose students to STEM at an early stage during their education as high school students engaged in mathematics and science activity are more likely to select a STEM major during their post-secondary education (Gottfried \& Williams, 2013).

Our team launched the first high-altitude balloon in December of 2013 by a group of university students majoring in chemistry, computer science, geology and psychology who were enrolled in the "Building Interactive Gadgets" course taught by one author of the current paper. Seeing how the four undergraduate students were engaged, we saw the potential of the high-altitude balloon experiment for high school and post-secondary students. To make the high-altitude balloon experiment accessible to Kindergarten to Grade 12 teachers and post-secondary instructors, a custom-built balloon kit with a complete set of instructions has been developed allowing educators to conduct experiments similar to what were described by Larson et al. (2009) in 2015. Our custom-built kit includes an onboard computer with an array of sensors measuring temperature, pressure, humidity, and motion as well as the options of gas sensors to measure ozone, ammonia, carbon monoxide, nitrogen dioxide and/or volatile organic compounds (VOC). Further, the onboard computer is open-source and fully expandable, allowing additional detectors and gas sensors. There is also an onboard camera to capture stunning near-space video footage, and a satellite-reporting global positioning system (GPS) device to help recover the flight equipment. So far, eleven high schools and post-secondary institutions across Canada, including a team from Nunavut, have successfully launched the balloon with their students.

Seeing the success of the high-altitude balloon experiment for our university students as well as our initial launch partners in high schools and post-secondary institutions, we reached out to on-reserve schools and Indigenous students in Saskatchewan. Indigenous students from on-reserve schools are underrepresented in post-secondary institutions, especially in science. In Canada, $86.3 \%$ of the population has completed high school compared to only $70 \%$ for Aboriginal people (Statistics Canada, 2017). Moreover, high school completion rates among First Nations students vary according to where they go to school as only four in 
10 First Nation young adults living on-reserve graduated from high school (Anderson \& Richards, 2016). Students attending on-reserve schools usually perform at a lower level on basic measures of standard academic performance compared to provincial results (Anderson \& Richards, 2016). This lower education achievement has been attributed to lower funding to on-reserve schools (Aikenhead, 2013). This inequitable funding results in fewer resources available to on-reserve schools. For example, $64 \%$ of schools on reserve do not have a fully equipped science lab and only $48 \%$ have access to fully equipped technology (Assembly of First Nations, 2012). This resource-constrained context may undermine exposure to rich educational opportunities in science. By bringing hands-on science experience to on-reserve schools, we hypothesized that the high-altitude balloon experiment will engage Indigenous students in science.

In 2016, we received a grant to launch high-altitude balloons in on-reserve schools to engage Indigenous youth in science and engineering. On May 26, 2016, we launched a helium balloon with over 200 students from an on-reserve school, followed by a presentation about the high-altitude balloon experiment. Since the balloon was launched near the end of the academic year, we were not able to return to do a follow up discussion with the students. Following the launch, students were perceived to be overwhelmingly excited about the experience of the balloon launch and the scientific study of the atmosphere. Thus, a project with additional balloon launches on on-reserve schools studying how the activity can effectively motivate Indigenous students in science and engineering was developed.

In July of 2016, we received another grant from the TD Friends of the Environment Foundation to engage youth in science and studying the environment in South Saskatchewan. With the availability of the new funding, we contacted science teachers and administrators in on-reserve schools in Saskatchewan for potential balloon launches. We were pleased to receive confirmations from two on-reserve schools that they were interested to participate in the balloon launches in the Fall of 2017. As the integration of Aboriginal content and perspectives is a critical factor in fostering better conceptual understanding and higher-level thinking in high school students (Kanu, 2007), it was important to invite an Elder during these visits to First Nations community schools. In this paper, the success and opportunities will be discussed as well as potential avenues to improve this experiment for on-reserve school students.

\section{Methods}

\subsection{Participants}

During the fall of 2017, First Nations community schools were contacted regarding their interest in participating in a high-altitude balloon activity. The discussions were done through phone calls or emails and the first two schools that confirmed their interest were selected for the project. The two schools are identified as School A and School B respectively here. Both School A and School 
B enroll students from Grades 1 - 12. School A is located in a small community and has an enrollment of approximately 100 students while School B has more than 200 students. Following initial conversations with a teacher, approval from the school principal was obtained. Arrangements were made with the schools for an Elder to be present during the balloon launch. Before visiting the schools, paper consent forms were sent by mail to the teachers. High school students (grades 9 to 12) interested in the project were asked to sign the consent form and have their parent/guardian sign the form. Teachers interested in the balloon launch activity were also asked to sign a consent form for their input in our survey. The survey was completed by students and teachers at the end of the activities. The project was conducted with approval from the Research Ethics Board at our university.

\subsection{Activities}

On October 5, 2017, we visited School A and collected the signed consent forms. The high-altitude balloon was launched in a field located next to the school and the whole school was invited to attend this activity. During the launch preparation, we explained the function of the sensors and showed the students the camera that was installed in the flight equipment. Some students helped with the launching by holding the balloon during the helium filling. After the launch, a workshop was organized in the school gymnasium with the high school students. During the workshop, we offered an introductory one-hour PowerPoint presentation describing the high-altitude balloon, the on-board sensors and their functions, how to interpret the environmental data, and images from previous balloon launches filmed with the camera. After our introductory presentation, an Elder, who was also present during the launch, shared his knowledge in a teaching circle about cardinal directions, birds, and stars. This spiritual enrichment was a unique way to connect Indigenous science to the high-altitude balloon experiment. During both presentations, students were encouraged to ask questions. The Elder was presented with tobacco to thank him for his knowledge. On October 26, 2017, we visited School B. Only one signed consent form had been returned by students at that time so it was decided to collect the consent forms at a later date. The balloon launch at this school followed the same steps as the first launch. After the launch, we offered the same introductory PowerPoint presentation in a classroom with the high school students. No Elder was available on that day.

The high-altitude balloon was equipped with a satellite-reporting GPS device to track its location in the lower atmosphere allowing us to locate the landing site. After its retrieval, a video was made showing images captured by the camera during the launch and its ascend at different altitudes. For the balloon launch with School A, because of a loose wire, the camera captured only a little over one hour of video footage missing the burst of the balloon as well as the descent of the payload. Environmental data were analyzed and graphs were plotted show- 
ing the effect of altitude on temperature and humidity. On November 16, 2017, we went back to School A and presented the data and the video to the students. Before showing them the data, students were asked if they could predict how temperature and humidity would vary with altitudes. Explanations and examples on how to interpret the data were provided. A date was scheduled with the School B to show them the same presentation but we were informed the morning of the selected date that only one student had filled out the consent form and there was no Elder available. Since our goal was to survey the students about their experience, we decided to cancel our second presentation at that school and no survey was completed.

\subsection{Survey}

After our data and video presentation, students who had previously been provided the consent forms were asked to complete the survey at School A. All students presented that day had provided a signed consent form. Our paper survey had separate sections for students and teachers. The completed survey was collected at the end of our second visit. Examples of questions on the student survey included the following: 1) What did you learn during the workshop with the Elder? 2) Rate how the workshop with the Elder and the participation of the balloon experiment changes your view of science; 3) What is an example of Indigenous knowledge that you learned during this project? and 4) What is an example of science that you learned during this project? Can you explain it to us? Examples of questions on the teacher survey included the following: 1) Rate your experience; 2) Would you be interested in launching another high-altitude balloon? 3) Rate your perception of how the participation of the balloon experiment changes the view of your students in science; and 4) How did you incorporate the high-altitude balloon experiment in your classroom? Students and teachers completed the survey at the same time. Qualitative answers were analyzed using thematic analysis where major themes were identified inductively. Participant phrasing was retained.

\section{Results}

Fourteen student participants from School A answered the survey and the data are summarized in Table 1 . Students generally agree that they learned more during the workshop with the Elder, with 6 students either agreed or strongly agreed, 5 neutral or undecided, and 2 students disagreed or strongly disagreed. Students also tend to agree that they learned more during the balloon launch activity, with 6 students either strongly agreed or agreed, 3 neutral or undecided, and 3 either disagreed or strongly disagreed. Students also tend to agree that they learn more during the data analysis once the payload was retrieved, with 6 students agreed or strongly agreed, 3 neutral or undecided, and 3 disagreed or strongly disagreed. There were slightly more students saying that they were more interested in science, with 5 students agreed or strongly agreed, 4 neutral or 
Table 1. Summary of student survey. The number of responses for each question is indicated.

\begin{tabular}{|c|c|c|c|c|c|}
\hline & Strongly agree & Agree & Neutral or undecided & Disagree & Strongly disagree \\
\hline I learned more during the workshop with the elder. & 2 & 4 & 5 & 0 & 2 \\
\hline I learned more during the balloon launch activity. & 3 & 3 & 3 & 2 & 1 \\
\hline $\begin{array}{l}\text { I learned more during the data analysis once we } \\
\text { retrieved the payload. }\end{array}$ & 3 & 3 & 3 & 2 & 1 \\
\hline I am more interested in science. & 2 & 3 & 4 & 2 & 1 \\
\hline I want to take more science classes. & 3 & 0 & 5 & 2 & 1 \\
\hline I am considering post-secondary education in science. & 3 & 2 & 2 & 4 & 1 \\
\hline I am considering a career in science. & 2 & 1 & 4 & 4 & 1 \\
\hline
\end{tabular}

undecided, and 3 disagreed or strongly disagreed. That being said, there is roughly the same number of students saying they would take more science classes after the activity than those who would not. Further, there were actually more students saying that they wouldn't consider post-secondary education science or a career in science after the activity that those who would. The total number of responses for each question may not add up to the sample size since students may not answer all questions.

In terms of learning, students tend to agree that they learned more from activities such as the workshop with the Elder, the balloon launch, and the data analysis session. The survey was done more than one month after the balloon launch and the initial presentation and the quality of some of the comments provided by the students was impressive. Students were asked what they learned during the workshop with the Elder, to provide examples of Indigenous Knowledge that they learned, what they learned from the project, what they liked the most of the project, and something new and interesting they learned from the project. Their responses are summarized in Table 2.

Two teachers from School A were also asked about their perception of how the participation of the high-altitude balloon experiment changes the view of their students. Though there were only two teachers participating in the survey, their responses were consistent with their students. The two teachers both agreed that their students learned more during the workshop with the Elder and during the balloon launch activity. They strongly agreed that their students learned more during the data analysis once the payload was retrieved. The two teachers either agree or strongly agree that their students are more interested in science after participating in the balloon experiment. Though one teacher strongly agreed that their students want to take more science classes after the balloon experiment, the other teacher was neutral about the effect. Finally, both teachers didn't think the balloon experiment makes any changes regarding their students of considering a post-secondary education in science and a career in science. 
Table 2. Written comments provided by students on the survey.

What did you learn during the workshop with the Elder?

"I learned about the wind".

"I learned about the Earth".

"I learned about the Earth and the measures of the Earth".

Provide an example of Indigenous Knowledge that you have learned during the project.

"The wind".

"One example could be that flying is teaching in indigenous history with birds".

Provide an example of science that you learned during the project.

"The wind is strong".

"The temperature that changes high in the sky".

"I have learned that the air is thinner in the ozone layer".

"Time, temperature, $\mathrm{km}$ of the balloon".

"At the certain height, two oxygen molecules break down and produces heat".

What did you like the most of the project?

"I liked the balloon launch it was cool".

"Watch the video cause we got to see how everything looked".

"I liked the data".

"Launch the balloon because it was pretty. Cool seeing how big it got".

"Balloon launch because it was cool".

"When we watched the video".

"When the balloon was in air because of the wind".

"The excitement, all the students and teachers were excited to see the science happening at the site; everyone cheering at the time of launch".

Tell us something new and interesting that you learned during the project.

"I learned about space more".

"I learned how big the balloon went and where it landed".

"How way up high the balloon can go".

"The wind".

"The above ground data like in weather conditions, temperature. What kind of things and dwellings exist around. We can see the things which have never been seen before (valleys)".

\section{Discussion}

Based on the results of the student and teacher surveys, the responses of the students and two teachers are consistent stating that the students generally learned more during the workshop with the Elder, during the balloon launch activity, and during the data analysis once the payload was retrieved. Although more students said that they were more interested in science, a majority of them stated that they would not consider a science post-secondary education or a science career. While the two pieces of data seem to contradict each other, the written comments provide more insights about the inconsistent results.

We did the surveys more than a month after the balloon launch and the workshop with the Elder. In spite of this prolonged time gap, a few students 
clearly remembered what they learned from the Elder and what we told them over a month ago. Further, many of them managed to provide a lot of details of what they liked most about the project as well as something new and interesting that they learned. These results support our hypothesis and show that the high-altitude balloon experiment and the presence of the Elder engaged students to learn more about science. That being said, we only had a brief interaction with the students and the balloon launch and subsequent presentations were not expected to change their view about science.

Thus, we are proposing the following to improve the impact of the high-altitude balloon experiment for Indigenous youth as well as the participation of student surveys especially for Indigenous communities.

\subsection{Integrate the High-Altitude Balloon Experiment in Longer Term Initiatives}

One limitation of the current project was the lack of student involvement during data analysis. Our project team visited the schools for 2 to 3 hours but there was no time for the students to work on the data by themselves. They were asked questions about what the data would look like but the analysis was already performed and students were presented with graphs instead of raw data. It would have been a more enriching experience if the students had to analyze the data by themselves under the project team mentorship. An example of such an initiative is the mini-med school for Aboriginal youth at the University of Calgary, Canada (Henderson, Williams, \& Crowshoe, 2015). During the half-day program, high school youth experiment with stethoscopes, learn to identify body organ on diagrams, read x-rays, and insert a laryngoscope in dummies under the mentorship of medicine students. This initiative provides hands-on activities for Aboriginal youth located in resource-limited environments where teacher burnout and constrained resources limit the exposure to potentially enriching career opportunities (Henderson et. al, 2015).

Another way to bring the high-altitude balloon experiment to its full potential is to integrate the experiment in summer science camp. Some of our high school partners have tried to get their students doing most of the balloon experiment on their own under the supervision of teachers. It would take a student team 1 - 3 days to assemble and fully test the balloon kit for launch. With the custom balloon kit and the availability of the complete set of instructions, the project would make an excellent hands-on research experience for Indigenous high school students who are participating in the summer camp.

Getting students directly involved in setting up the balloon launch is more effective to engage them than participating in the balloon launch. Further, after the balloon is launched, the students will go to retrieve the payload with their teachers. We have found that students love the experience of going to the field and retrieving the payload because it is difficult to precisely predict where the payload will land. As a result, the recovering process is an adventure providing students valuable real-life science experience. Under normal conditions, it would 
take 1 - 2 days to launch the balloon and recover the payload. Once the payload is retrieved, students will be eager to analyze the environmental data and the video images collected on the payload. Depending on the experiments that students may choose to perform, it will take a few hours to a few days to complete the analysis of the data. Then, students may present and report the results at the end of the science camp to the other attendees.

The integration of the high-altitude balloon experiment in summer camp is expected to benefit the students from the on-reserve schools providing them unprecedented opportunity to conduct scientific research and building their interest in science. The high-altitude balloon experiment would make a perfect week-long activity.

\subsection{Incorporating the Balloon Experiment to High School Science Curriculum}

As mentioned, post-secondary institutions have been incorporating high-altitude balloon experiment in university science and engineering courses. More recently, educators have begun using the balloon experiment to engage middle school and high school students. However, many of the engagements, just like our engagement with on-reserve schools, lasted only for a few hours focusing on the scientific research rather than specific topics in high school science curriculum. As mentioned by Coleman and Mitchell (2014), while students who participated in the full high-altitude balloon experiment were motivated and benefited from the experience, those who were involved in the one-off events didn't get significant benefits.

Many rural schools and on-reserve schools often have limited resources. Thus, students do not have access to a lot of hands-on experiments especially in science. Resource challenged schools may benefit from partnering with local universities or science-based organizations to create more opportunities for their students. Exposure to authentic STEM activities could impact student schooling success and their future post-secondary participation in STEM programs (Gottfried \& Williams, 2013).

Focusing on bringing research experience along with the balloon experiment, however, may not bring the full potential to these students. Instead, by incorporating the high-altitude balloon experiment to high school science curriculum will be more beneficial. As mentioned by Tillman et al. (2008), high-altitude balloon experiments can be incorporated into the high school science and mathematics curriculum. Recently, the authors of the current paper submitted a manuscript for publication describing the incorporation of the high-altitude balloon experiment to high school science classrooms discussing how the balloon experiment can be used for specific chemistry topics including gases, thermochemistry, heat capacity, enthalpy of reaction, bond formation, and chemical equilibrium. In addition to chemistry topics, the high-altitude balloon experiment can be incorporated to high school environment science and physics. The science topics that can be connected to the high-altitude balloon experiment are 
summarized in Table 3. Integration of the high-altitude balloon experiment along with its related Aboriginal perspectives throughout the academic year curriculum and pedagogy (and not just as a separate topic), has a better chance of increasing student performance and understanding in high school students (Kanu, 2007).

\subsection{Improving the Survey and Its Participation}

In the current study, participants were surveyed only once at the end of the experiment. There was no pre-experiment survey to compare our post-experiment responses with. In the future, students will be surveyed before and after the balloon launch to improve our research. For questions regarding their interest in science, whether they want to take more science classes, post-secondary education in science, and career in science, students will be asked before and after the balloon experiment to check whether the balloon experiment makes any real changes. Rather than depending on self-reporting of what students perceive of their interest, the pre- and post-survey will offer us more information about how we can better apply the high-altitude balloon experiment for high school students on reserves.

The rate of return of consent forms was very low at School B and the data and video presentation was cancelled at that school due to the low number of returned consent forms (only one consent form was returned). In our active consent procedure, parents received the consent form along with a description of the study describing its benefits and risks. The parents then indicate whether they will let their child participate in the activity or not, signs the form and returns it to the school which then gives it to us. Following a discussion with the school principal, it was suggested to shorten the consent form. The initial consent form had four pages with a letter of information followed by the actual

Table 3. High school science topics that can be connected to the high-altitude balloon experiment.

\begin{tabular}{cc}
\hline Subject & Topics \\
\hline Environmental Science & Earth's atmosphere \\
Air quality & Pollution \\
Chemistry & Gases and atmosphere \\
& Heat and thermochemistry \\
& Enthalpy of reaction \\
& Electromagnetic radiations \\
& Chemical bonding \\
& Chemical equilibrium \\
& \\
& Newton's laws of motion \\
& Gravitational field \\
& Law of conservation of momentum
\end{tabular}


consent form. After contacting the Research Ethics Board at our university, a shortened form that has all the required information but was only 2 pages long was prepared. It is hoped that this shortened version will increase the parents' response rate to our survey. Prior studies with high school participants have found that the rate of return of consent forms is higher when parents received the consent and accompanying materials during a school meeting than when the forms were distributed in the classroom and sent home with students (Stein et al., 2007). This difference might be explained by the fact that students don't bring the forms home and parents don't see it or that students don't return signed forms back to the school. Parents might pay more attention to a consent form if it is distributed by school officials than if they receive it from their child (Stein et al., 2007). Attaching the consent form to a letter of support from the school principal and to other documents that the parents had to sign and return to the school have also been shown to increase return rates (Ji, Pokorny, \& Jason, 2004). Moreover, Indigenous people are less inclined to participate in research projects because of the perception that research projects in the past were done without their voluntary consent (Castellano, 2004). By having more participants in the survey, more valuable information can be processed.

\section{Conclusion}

In this study, successes, opportunities and challenges of a high-altitude balloon experiment with on-reserve schools are discussed. In a survey completed after the experiment, students agreed that they learned more during the workshop with the Elder, the balloon launch activity, and the data analysis after the payload retrieval. Slightly more students said they were more interested in science but about the same number of students said they would take more science classes while more students indicated they would not consider post-secondary science education. In their written comments, however, many students were able to describe what they learned and give examples of Indigenous knowledge shared by an Elder during the activity. For future similar activities, it is recommended to integrate the experiment in longer term initiatives such as multi-day workshops or summer camps, to incorporate the experiment into the high school curriculum and not as a separate activity, and to provide a concise consent form and supply document to parents during school meetings or attached with a letter of support from the school principal along with other documents from the school that parents have to sign and return.

\section{Acknowledgements}

We would like to thank the students, teachers, staff, and the Elder from the two on-reserve schools who participated in the high-altitude balloon experiment. The funding for the development of the balloon kit was supported by an NSERC PromoScience grant. The balloon launches from the on-reserve schools were made possible by the University of Regina Indigenous Fund and the TD Friends 
of the Environment Foundation grant. Finally, publication support was provided by the University of Regina President's Publication Fund.

\section{Conflicts of Interest}

The authors declare no conflicts of interest regarding the publication of this paper.

\section{References}

Aikenhead, G. S. (2013). Science, Technology, Engineering and Mathematics Education and Related Employment for Indigenous Students and Citizens of Saskatchewan. Melbourne: Australian Council of Learned Academies.

Anderson, B., \& Richards, J. (2016). Students in Jeopardy: An Agenda for Improving Results in Band-Operated Schools. Toronto, ON: C.D. Howe Institute. https://doi.org/10.2139/ssrn.2724140

Assembly of First Nations (2012). 2011 AFN School Survey Results. http://www.afn.ca/2013/08/28/afn-2011-education-survey-results/

Beck-Winchatz, B., \& Bramble, J. (2014). High Altitude Ballooning Student Research with Yeast and Plant Seeds. Gravitational \& Space Biology, 25, 117-127.

Castellano, M. B. (2004). Ethics of Aboriginal Research. Journal of Aboriginal Health, 1, 98-114.

Coleman, J. M., \& Mitchell, M. (2014). Active Learning in the Atmospheric Science Classroom and beyond through High Altitude Ballooning. Journal of College Science Teaching, 44, 26-30. https://doi.org/10.2505/4/jcst14_044_02_26

Faltersack, B., Maraccini, J., Petrie, J., \& Rasmussen, T. T. (2016). 2016 Elijah High Altitude Balloon Launch Team Summer Proceedings Report. In Proceedings of the 26th Wisconsin Space Conference: Beyond the Horizon. Kenosha, WI: Wisconsin Space Grant Consortium.

Fong, B. N., Kennon, J. T., \& Roberts, E. (2016). Integrating BalloonSAT and Atmospheric Dynamic Concepts into the Secondary Classroom. The Physics Teacher, 54, 264-267. https://doi.org/10.1119/1.4947150

Gottfried, M. A., \& Williams, D. N. (2013). STEM Club Participation and STEM Schooling Outcomes. Education Policy Analysis Archives, 21, 1-23.

Henderson, R. I., Williams, K., \& Crowshoe, L. (2015). Mini-Med School for Aboriginal Youth: Experiential Science Outreach to Tackle Systemic Barriers. Medical Education Online, 20, 1-7. https://doi.org/10.3402/meo.v20.29561

Hike, N., \& Beck-Winchatz, B. (2015). Near Space Science: A Ballooning Project to Engage Students with Space beyond the Big Screen. The Science Teacher, 82, 29-36.

Ji, P. Y., Pokorny, S. B., \& Jason, L. A. (2004). Factors Influencing Middle and High Schools' Active Parental Consent Return Rates. Evaluation Review, 28, 578-591.

https://psycnet.apa.org/doi/10.1177/0193841X04263917 https://doi.org/10.1177/0193841X04263917

Kanu, Y. (2007). Increasing School Success among Aboriginal Students: Culturally Responsive Curriculum or Macrostructural Variables Affecting Schooling? Diaspora, Indigenous, and Minority Education, 1, 21-41.

Larson, S. L., Armstrong, J. C., \& Hiscock, W. A. (2009). The First Frontier: High Altitude Ballooning as a Platform for Student Research Experiences in Science and Engineering. American Journal of Physics, 77, 489-497. https://doi.org/10.1119/1.3097775 
Saad, M. E. (2014). Progressing Science, Technology, Engineering, and Math (STEM) Education in North Dakota with Near-Space Ballooning. Master's Thesis, Grand Forks, SD: University of North Dakota.

Statistics Canada (2017). Education in Canada: Key Results from the 2016 Census. http://www.statcan.gc.ca/daily-quotidien/171129/dq171129a-eng.htm

Stein, B. D., Jaycox, L. H., Langley, A., Kataoka, S. H., Wilkins, W. S., \& Wong, M. (2007). Active Parental Consent for a School-Based Community Violence Screening: Comparing Distribution Methods. The Journal of School Health, 77, 116-120. https://doi.org/10.1111/j.1746-1561.2007.00180.x

Straub, J., Ingwalson, G., \& Fevig, R. (2013). A Design for Inspiring Students with Near-Space Exploration. Journal of Aviation/Aerospace Education \& Research, 23, 35-48. https://doi.org/10.15394/jaaer.2013.1597

Taylor, J. M. Jr., \& Nero, D. A. (2017). Project HALON: Engaging Secondary Students in High Altitude Ballooning Experiments. In IEEE International Conference on Electro Information Technology (pp. 587-592). Piscataway, NJ: Institute of Electrical and Electronics Engineers. https://doi.org/10.1109/EIT.2017.8053432

Tillman, K., Roberts, E., \& Fuller, T. (2008). Students at the Edge of Space: A Collaborative Program Using BallonSats Allows Students to Investigate Space. The Science Teacher, 75, 37-43.

Voss, H. D., \& Dailey, J. (2011). High Altitude Balloon Curriculum and Hands-On Sensors for Effective Student Learning in Astronomy and STEM. Earth and Space Science: Marking Connections in Education and Public Outreach, 443, 340-344. 